\title{
Cylinder Valve Device
}

National Cancer Institute

\section{Source}

National Cancer Institute. Cylinder Valve Device. NCI Thesaurus. Code C50259.

A valve designed to regulate the flow from a storage cylinder. 